\title{
Micro-Atividades Tecnológicas Para o Ensino Médio Integrado
}

\author{
Anderson Paulo Silva, Tiago L. A. Machado, Gabriela Albuquerque Maciel \\ Centro de Estudos em Sistemas Avançados do Recife - C.E.S.A.R \\ Rua Bione - 220 - Cais do Apolo, Bairro do Recife - Recife - PE - Brazil \\ \{aps, tlam,gam2\}@cesar.org.br
}

\begin{abstract}
This article describes a series of actions called Micro-Activities that aim to find ways of integrating content from different disciplines in high school, based on Information and Communication Technology (ICT) resources. Its main objective is to make the content taught in a more dynamic and engaging classroom, while integrating more than one discipline using specific content. During the research were obtained applications for mobile devices that could assist in the learning of various disciplines and improve a different way of using flowcharts in textual development. At the end of the article reports that points education professionals, as a result, improving the participation of students and the points of possible improvements for future research are presented. At the end of the article are presented reports of education professionals, that points as result, improving the participation of students and possible improvements for future research.
\end{abstract}

Resumo. Este artigo descreve uma série de ações chamadas MicroAtividades, que visam encontrar meios de integração de conteúdos de disciplinas distintas, no ensino médio, através de recursos baseados na Tecnologia da Informação e Comunicação (TIC). Seu principal objetivo é tornar o conteúdo ministrado em sala de aula mais lúdico, dinâmico e envolvente, enquanto integra mais de uma disciplina por meio de conteúdos especificos. No decorrer da pesquisa, foram obtidas aplicações para dispositivos móveis que auxiliam no aprendizado de diversas disciplinas. Ao fim do artigo, são apresentados relatos de profissionais de educação que apontam, como resultado, a melhoria da participação dos educandos e os pontos de possíveis melhorias para pesquisas futuras.

\section{Introdução}

Ao longo dos últimos anos, muitas pesquisas foram realizadas sobre o tema Ensino Médio Integrado, possuindo várias interpretações. Uma das mais comuns diz respeito às práticas de tal integração ocorrer em nível de interdisciplinaridade, buscando uma relação de reciprocidade e mutualidade. Dessa forma e com o foco em atitude, a colaboração entre as diversas disciplinas conduz a uma interação que segundo [Fazenda 2011] leva a um efetivo trabalho interdisciplinar.

A ênfase na atitude é defendida por [Freire 2008] tratando-a como o compromisso do homem com o mundo pelo caráter permanente de uma educação de 
qualidade. O que reforça o discurso de [Fazenda 2011], no qual opina que uma educação integrada e interdisciplinar torna o homem capaz de compreender e modificar o mundo, pois lhe proporciona a aplicação no dia a dia do conhecimento obtido em sala. Entretanto, [Freire and Shor 1986] consideram como ameaça à busca de uma integração, na forma proposta por [Fazenda 2011], a ausência da prática de experimentação nas escolas.

Considerando, as abordagens encontradas em [Fazenda 2011; Freire and Shor 1986], nesta pesquisa, foram realizadas, dentro de um ambiente de ensino médio técnico, observações acerca das dificuldades de envolvimento encontradas pelos alunos e pelos professores em relação a diversas disciplinas (tanto técnicas e como regulares). No que tange ao processo de integração, foram propostas formas diferenciadas de ensino integrado com auxílio de recursos baseados na tecnologia da informação e comunicação (TIC), uma vez que tais recursos são ferramentas de interesse inegável enquanto objeto de pesquisa e incentivam, justificadamente, esforços no sentido de sua adoção como instrumento pedagógico [Meira and Falcão 1997].

Ambientes que usem elementos lúdicos e tecnológicos se mostram ideais para o aprendizado, uma vez que são grandes indicadores de mudanças tecnológicas e culturais, como elucida [Squire 2008]. Além disso, também é importante considerar a inserção forte desta geração em tal meio [Constance and Squire 2013], visto que a inclusão da tecnologia na educação gera ênfase no aprendizado por meio da ação [Meira and Falcão 1997]. Esta inclusão tecnológica envolve os indivíduos através de conceitos que lhes desperta interesse e, dessa forma, o aprendizado tangencial [Portnow and Floyd 2008], que visa facilitar a obtenção de conhecimento, através da exposição do indivíduo a um determinado conteúdo por um meio amigável ou ao qual este seja simpático, é evidenciado.

Dentro deste contexto, visando colaborar com os estudos previamente mencionados, este artigo apresenta a pesquisa sobre ensino médio integrado com o auxilio de ferramentas de TICs, realizada no projeto Núcleo Avançado em Educação (NAVE), que funciona na Escola Técnica Estadual Cícero Dias em Recife, PE, onde os alunos estudam, em horário integral, disciplinas do ensino médio de forma concomitante a disciplinas técnicas de desenvolvimento de jogos.

Nas próximas seções, apresentamos o referencial teórico, a metodologia, os resultados e as considerações finais com propostas para trabalhos futuros.

\section{Referencial Teórico}

Muitas vezes, a natureza abstrata de uma disciplina ou um determinado conteúdo acaba por promover a falta de estímulo e, como consequência, o baixo rendimento escolar [Meira and Pinheiro 2012]. Como solução para este tema, alguns pesquisadores têm proposto formas mais dinâmicas e integradas de disciplinas [Fazenda 2011; Freire e Shor 1986]. Outros pesquisadores, por sua vez, se baseiam no uso de diversas TICs inseridas em novas formas de ensino para tornar o ambiente escolar mais dinâmico e integrado [Criso et al. 2011]; [Antonoglou et al. 2011].

Assim, as TICs apresentam-se como um valioso e "poderoso" recurso didático que pode enriquecer e diversificar significativamente o processo de ensino e 
aprendizagem, o que colabora para trabalhar e desencadear as relações envolvidas nas novas formas de pensar e aprender a educação de maneira mais integrada, participativa e cooperativa. [Brignol 2004]. Portanto, as TICs podem auxiliar no desenvolvimento do ensino médio integrado que de acordo com [Ramos 2008], lança a oportunidade do "Currículo Integrado", pois este pode contemplar uma compreensão global do conhecimento e de promover maiores parcelas em relação à interdisciplinaridade na sua construção. Entretanto, a mesma também reconhece que essa oportunidade é cercada de muitos desafios, dentre os quais podemos destacar: a integração entre os professores, entre os conteúdos e a metodologia das disciplinas adotadas, entre a programação dos cursos e a expectativa dos alunos, além da formação recebida e da execução das funções posteriormente assumidas [Fazenda 2011].

Assim, objetivando contribuir com as pesquisas supracitadas, foram pensadas formas de integração, chamadas de Micro-Atividades, que se utilizam de conceitos de TICs no desenvolvimento de atividades integradas. Estas serão apresentadas nos capítulos seguintes.

\section{Metodologia}

A metodologia consiste na criação das Micro-Atividades, que são meios de integração entre duas ou mais disciplinas do ensino médio e técnico através de conceitos de TICs.

Participaram como colaboradores da elaboração, condução e avaliação das atividades seis professores de disciplinas do ensino médio e quatro professores do ensino técnico. Cada experiência contava com determinadas datas que eram reservadas para que os professores pudessem trabalhar juntos, orientando os alunos e auxiliando-os no desenvolvimento do projeto. No decorrer da pesquisa as MicroAtividades foram divididas em três: Fluxogramas, Ensino Médio no Smartphone e Artefatos Digitais Educacionais.

A seguir, as particularidades sobre a metodologia de cada Micro-Atividade desenvolvida na pesquisa serão apresentadas.

\subsection{Micro-Atividade 1 - Fluxogramas}

Para esta atividade, foi escolhida a disciplina Português, devido a sua importância curricular e a uma série de problemas no desenvolvimento e compreensão de textos pelos educandos que foram relatados por professores da disciplina através de entrevistas. Assim, a Micro-Atividade aqui relatada, utiliza-se de Fluxogramas como ferramenta de auxílio na construção de redações para a disciplina Português. Segundo [Slack et al. 1997], um fluxograma consiste em uma técnica de mapeamento que permite o registro de ações de algum tipo e pontos de tomada de decisão que ocorrem num fluxo real. Esta técnica é utilizada como recurso em diversas áreas, sendo para o desenvolvimento de software um conceito padrão [Alias et al. 2010]. O mesmo é largamente utilizado em engenharia de processos e gerenciamento de projetos, principalmente por apresentar os diversos caminhos que estes podem ter.

O propósito de utilizar os fluxogramas foi fazer com que os alunos explorassem novas possibilidades para as ideias desenvolvidas num primeiro momento, por meio das várias direções que um fluxograma pode gerar. 
O desenvolvimento deste experimento se deu por conta de relatos de problemas encontrados durante o desenvolvimento de textos nas turmas do primeiro ano do ensino médio pela professora de Português, tais como:

- Convergência de ideias (os alunos não conseguiam desenvolver novos rumos em seus textos, voltando sempre ao mesmo ponto);

- Dificuldade para vislumbrar novas possibilidades;

- Dificuldade na introdução e conclusão dos textos.

Para tanto os alunos deveriam propor contextos e acontecimentos diferentes em seus textos. Como exemplo utilizado em sala de aula para apresentar aos educandos o funcionamento da experiência, foi utilizado o fluxograma abaixo que mostra o desenvolvimento da música "Hey Jude" dos Beatles.

hey Jude

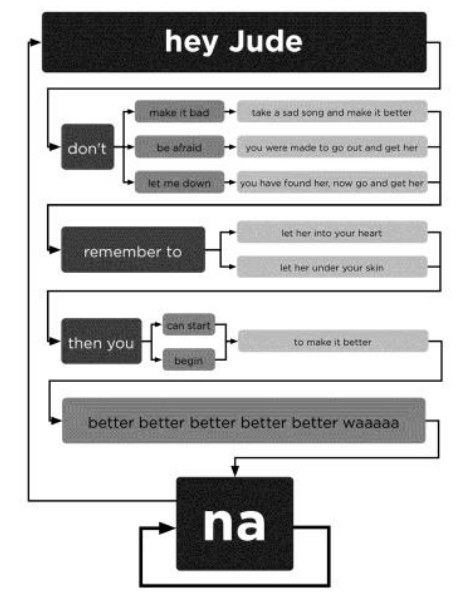

Figura 1. Exemplo de fluxograma aplicado a texto [NASCIMENTO, 2013]

$\mathrm{O}$ experimento foi realizado em três etapas. Em um primeiro momento foram analisados pela professora de Português os textos produzidos em sua disciplina sem o uso do fluxograma. Este passo serviu como introdução para a atividade e iria definir um ponto inicial da experiência de cada aluno. Assim, serviu como base para avaliar se ocorreu ou não alguma alteração significativa do texto nas atividades seguintes. Em um segundo momento foi realizada uma fase de experimentação, onde os alunos usariam o fluxograma para tentar produzir textos diferenciados. Esta etapa funcionou como uma fase de aprendizado, visto que a introdução de uma abordagem diferenciada causou inicialmente certo impacto no seu desenvolvimento, mas que após algumas experimentações foi bem aceita. E por último, já familiarizado com a técnica o aluno produziu o texto definitivo, com o objetivo de evitar os erros cometidos antes da aplicação da metodologia.

\subsection{Micro-atividade2 - Ensino Médio no Smartphone}

Em outra atividade os alunos do terceiro ano do ensino médio/técnico trabalharam com conceitos de programação para smartphones, requisito obrigatório da disciplina técnica, 
e conteúdos do ensino médio, usados como meio de integração entre as disciplinas. $\mathrm{O}$ objetivo foi envolver os educandos em conteúdos vivenciados nas disciplinas Física, Matemática, Artes, Biologia, Português e História através da produção de aplicações para dispositivos móveis Android [Android 2013].

A atividade ocorreu em duas etapas: na primeira etapa os alunos assistiram aulas sobre os assuntos básicos necessários para criar uma aplicação para smartphones; na segunda etapa, os alunos em grupo, implementaram seus projetos através do kit de desenvolvimento Android - Android SDK [Android, 2013]. As propostas seguiam os temas que estes já estudaram em disciplinas regulares, como: Leis de Newton, Hidrostática e Artes (Pintura) (Figura 2). Nesse momento, os alunos recorreram a fontes de informação externas a sala de aula e, principalmente, ao professor da disciplina, cujo tema estava em desenvolvimento no projeto do(s) aluno(s). O professor (da disciplina técnica ou do ensino médio), por sua vez, tinha como papel fundamental orientar e tirar possíveis dúvidas durante a construção do projeto, dentro da sua área de conhecimento. Ao final das duas etapas, os alunos apresentaram e disponibilizaram as aplicações para avaliação, a qual considerava os aspectos técnicos envolvidos no desenvolvimento do projeto e a correção dos conteúdos apresentados.
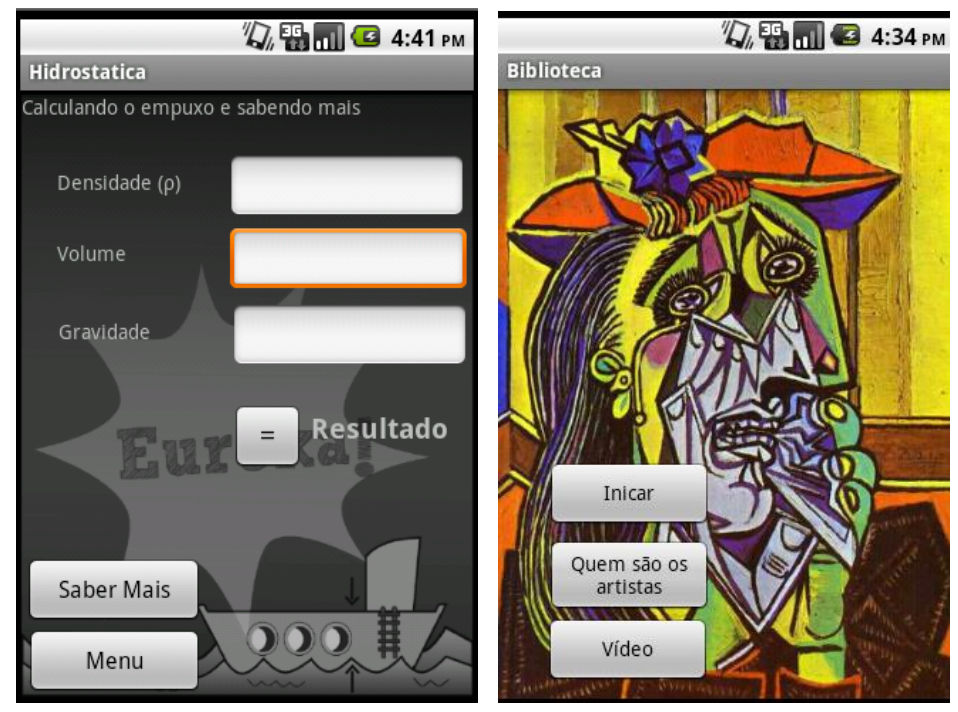

Figura 2. Aplicativos produzidos pelos alunos.

\subsection{Micro-atividade 3 - Artefatos digitais educacionais}

A atividade de artefatos digitais educacionais teve como foco o desenvolvimento de aplicativos para diversas plataformas (smartphones, computadores pessoais e internet) através da ferramenta Unity 3D [Unity 2013] que abordassem áreas distintas, tais como: Saúde, Exatas e Humanas. A ideia central deste experimento foi trazer a integração de conteúdos por meio da maior interação entre diversas áreas do conhecimento ao mesmo tempo que objetivou atrair a atenção dos educandos em um projeto diferenciado. Os professores do ensino regular foram chamados para participar do projeto, não apenas para resolução de dúvidas, mas para dar dicas de melhorias nos projetos, participando ativamente das diversas etapas de desenvolvimento (concepção de atividades, reuniões de alinhamento, acompanhamento dos educandos, avaliação e apresentação final). 
A meta foi desenvolver aplicativos que estivessem relacionados com uma das três áreas (Saúde, Exatas e Humanas), visando que os professores dos cursos técnicos e os professores das áreas afins trabalhassem em conjunto. Os alunos, por sua vez, deveriam desenvolver o projeto, sob a orientação dos professores e pesquisar os diversos conteúdos estudados. Dessa forma, todos os participantes teriam a ganhar, uma vez que os alunos iriam ser orientados pelos professores em suas pesquisas e estes iriam trabalhar e avaliar colaborativamente os temas de ensino de diversas disciplinas ao mesmo tempo.

\section{Resultados}

Nesta seção encontram-se os resultados das Micro-Atividades, que foram obtidos a partir do relato dos professores que participaram da execução desta pesquisa.

Na seção 4.1 discutiremos o uso de fluxogramas para produção de textos, enquanto a seção 4.2 comenta as técnicas de produção de aplicações para Smartphones para a integração de disciplinas, a seção 4.3 comenta a Micro-Atividade de artefatos digitais educacionais e a seção 4.4 apresenta comentários de professores que colaboraram na pesquisa.

\subsection{Fluxograma para produção de textos}

Após a observação das três etapas apresentadas na seção 3.1, foi possível perceber melhorias em boa parte dos alunos. De acordo com os relatos obtidos com a professora de português, os textos construídos apresentaram maior diversidade de ideias, reduzindo a convergência de temas. Contudo, alguns educandos desenvolveram textos muito curtos e com pouca diferença textual durante o experimento.

Desta forma, esta Micro-Atividade apresenta indicadores de melhoria na produção textual dos educandos, contudo uma vez que uma parcela menor destes produziram textos com os mesmos problemas identificados anteriormente, fica evidente a necessidade de mais experimentos com intuito de identificar os principais pontos a serem melhorados.

\subsection{Ensino médio no smartphone}

Com relação à construção de aplicações para smartphones, em muitos momentos, os alunos sentiram a necessidade de solucionar dúvidas com seus professores, pois precisaram confirmar e, se possível, aprimorar as informações obtidas em sites e livros para produção de aplicações que fossem uteis e atuais. Dessa forma, os alunos eram encorajados a consultar os responsáveis das disciplinas regulares e esclarecer dúvidas. Os professores, por sua vez, relataram que os alunos foram além do que eles esperavam, os consultando inclusive para questões mais complexas que não foram exigidas. Assim, foi possível observar um maior envolvimento dos alunos na busca por conhecimento, tanto das disciplinas técnicas, quanto das regulares. 


\subsection{Artefatos digiais}

Um dos principais resultados positivos obtidos foi o maior envolvimento por parte dos professores e educandos, o que facilitou em termos de avaliação e revisita a conteúdos já estudados, uma vez que todos estavam reunidos e poderiam discutir juntos o melhor caminho a ser tomado após cada etapa da experiência. Segundo um dos professores, tal colaboração acabou exercendo um positivo impacto na forma de participação dos alunos nas aulas e nos resultados apresentados em suas disciplinas.

\subsection{Considerações dos Professores Colaboradores da Pesquisa}

Nesta seção, são apresentadas as considerações obtidas com os professores de disciplinas regulares que participaram das Micro-Atividades, onde foi possível verificar as suas opiniões acerca dos resultados obtidos e qual o impacto que a proposta causou às suas aulas e aos alunos. Para isso, realizamos entrevistas semiestruturadas. Um dos professores ressaltou o entusiasmo de alguns alunos com tal prática.

“Eles mostraram (entusiasmo) sim, porque foi uma atividade lúdica, que fugiu do tradicional e isso interessa a eles. E a gente percebe, até, que muitos vão além, muitos alunos procuram livros para saber mais sobre o assunto - até coisas que a gente não cobra na aula."

Entretanto, o mesmo professor, revelou alguns problemas, sendo o tempo de aula e a ausência de planejamento da escola, que não fornece o tempo adequado para tais atividades, os mais evidentes segundo suas observações abaixo.

"Uma das maiores dificuldades é o tempo que a gente tem pra trabalhar com o educando - porque ele tá sempre tendo aula e mesmo em dia que ele tem tempo, as vezes são dias que eu trabalho quase sem nenhum intervalo. No curso técnico eles têm um momento que eles se reúnem pra produzir - mas eu não tenho esse tempo e fica difícil pra mim. Falta também um planejamento (por parte da escola), porque as vezes eu estou seguindo alguma coisa e vocês (técnico) outra, então precisamos de um planejamento único que permitam esses momentos de produção."

Já um outro professor, também acha que as Micro-Atividades ainda não trouxeram a plena integração para a escola, mas percebe a melhora do processo e revela que a constante mudança no quadro de professores ameaça a boa continuidade do processo. 
"Acho que tudo é um processo. Essa integração não aconteceu 100\%, ela ainda está acontecendo. Mas, sem dúvida, quanto ao envolvimento, eu vejo que há benefícios tanto no regular quanto no técnico. E ai há um dialogo mais próximo do professor da base comum com o técnico. Eu acho que ainda há muito para melhorar, a proposta ainda é nova e há muitas trocas de professores, o que acaba quebrando esse ritmo (da integração)."

Desta forma, foi possível observar que a maioria dos professores percebeu melhoras no envolvimento dos alunos e que as Micro-Atividades possibilitam meios de integração, embora ainda seja necessário uma quantidade maior de testes, para que tais atividades possam ser aprimoradas.

\section{Considerações finais}

Este artigo apresentou a proposta de Micro-Atividades como forma de experimentar e descrever novos meios de proporcionar a integração de disciplinas através do melhor aproveitamento de disciplinas técnicas e regulares. Em todas as atividades, a característica de construção do conhecimento por meio da ação [Meira e Falcão 1997] foi predominante, originando um maior envolvimento dos alunos e professores, apresentando característica do aprendizado tangencial de acordo com os postulados de [Portnow e Floyd 2008] e atestado pelos profissionais participantes da pesquisa.

Embora as turmas tenham apresentado facilidade em trabalhar com mais de uma disciplina ao mesmo tempo por meio dessas atividades, nem todos os alunos conseguiram segui-las adequadamente como informado por alguns professores, que indicaram o curto tempo e o mau planejamento da escola para a atividade como fatores que precisam ser ajustados para uma maior adesão. Além disso, o estudo também gerou artefatos educacionais que podem ser utilizados por outras escolas.

No que tange a integração entre os professores, foi possível observar que ainda há certa resistência. Mas, de acordo com os relatos obtidos, também foi possível observar que as Micro-Atividades apresentaram pontos positivos neste processo e o diálogo entre o professor regular e o técnico foi melhorado.

Como trabalhos futuros, indicamos que novos métodos de avaliação sejam empregados para avaliar o resultado das Micro-Atividades, como grupos de foco que identifique ganhos e perdas tanto para estudantes quanto professores, pois nesta pesquisa foi utilizada apenas entrevista dos profissionais envolvidos, além disso, acredita-se que variáveis, já mencionadas, como tempo dos projetos, complexidade das tarefas e oportunidades de planejamento providenciadas pela escola precisam de mais atenção, reavaliação e flexibilidade para permitir mais contatos dos professores com os alunos e entre si para atingir uma integração de maior sucesso. 


\section{Agradecimentos}

Agradecemos ao Instituto Oi Futuro - Projeto NAVE por sua iniciativa e incentivo em pesquisa nas áreas de educação, TI e jogos, à Escola Técnica Estadual Cícero Dias por proporcionar um ambiente propício à inovação, aos dedicados alunos desta escola pelo singular comprometimento em suas atividades, ao C.E.S.A.R. por todo apoio e motivação que recebemos, a todos que fazem deste projeto possível e aos que passaram e passam por nossas vidas e deixam suas marcas pessoais ou profissionais.

\section{Referências}

Alias, C., Darte, A., Feautrier, P. and Gonnord, L. (2010) "Multi-dimensional rankings, program termination, and complexity bounds of flowchart programs". In: Proceedings of the 17th international conference on Static analysis (SAS'10), Springer-Verlag, Berlin, p. 117-133.

Android, 2013. "Google Android">android.com>: Acessado em: 13 de dezembro 2013

Antonoglou et al. 2011. L. D. Antonoglou, N.D. Charistos, M. P. Sigalas. (2011) "Design, development and implementation of a technology enhanced hybrid course on molecular symmetry: Students' outcomes and attitude”. In: Chemical Education Research and Practice, vol. 12, 454 - 468, 2011.

Brignol, 2004. S. M. S. Brignol. (2004) "Novas tecnologias de informação e comunicação nas relações de aprendizagem da estatística no ensimo médio". 2004. Disponível em: http://redeabe.org.br/Monografia.pdf Acesso em 07 dez. 2013

Constance and Squire, 2013. S. Constance, K. Squire. (2013) "Videogames and Learning"; Coursera online course, University of Wisconsin-Madison, Wisconsin, 2013.

Crisp et al., 2011. M. G. Crisp, S.H. Kable, J. R. Read, M. A. Buntine. "The need for innovative methods of teaching and learning chemistry in higher education reflections from a project of the European Chemistry Thematic Network". In: Chemical Education Research and Practice, vol. 12, 469, 2011.

Fazenda, 2011. I. C. A. Fazenda, "Integração e Interdisciplinaridade no Ensino Brasileiro: efetividade ou ideologia, 6a Edição" São Pualo: Edições Loyola, 2011.

Freire e Shor, 1986. P. Freire, I. SHOR, "Medo e Ousadia: o cotidiano do professor"; São Paulo, Ed. Paz e Terra, 1986.

Meira e Falcão, 1997. L. Meira, J. Falcão. "O Computador como Ferramenta Instrucional"; Revista Brasileira de Estudos Pedagógicos (1997) vol. 78, n.188-190, p. 236-261, 1997, Brasil.

Meira, e Pinheiro, 2012. L. Meira, M. Pinheiro. "Inovação na Escola". In: anais do XI Simpósio Brasileiro de Games e Entretenimento Digital, SBGAMES. Brasília, 2012

Nascimento, F. O jovem escritor, 2013. Disponível em: < http://ojovemescritor.com/2011/03/04/fluxograma-the-beatles-hey-jude/>: Acessado em: 07 de agosto 2013 
Portnow e Floyd, 2008. J. Portnow,; D. Floyd. (2008) "The Power of Tangential Learning”. $\quad$ http://www.edge-online.com/features/power-tangential-learning/. Visualizado em 06 de Novembro de 2013.

Slack et al., 1997. N. Slack, S. Chambers, C. Harland, A. Harrison, R. Johnston. (1997) "Administração da Produção". Editora Atlas, SP.

Squire, 2008. K. Squire, (2008) "Video Games and Education: Designing learning systems for an interactive age", University of Wisconsin - Madison Academic ADL Colab, Wisconsin.

Unity, 2013, "Unity"<unity3d.com>: Acessado em: 11 de dezembro 2013 